\title{
OPEN Silver ions cause oscillation of bacterial length of Escherichia coli
}

\author{
Venkata Rao Krishnamurthi ${ }^{1}$, Jingyi Chen ${ }^{2,3}$ \& Yong Wang ${ }^{1,3,4}$
}

Received: 14 November 2018

Accepted: 30 July 2019

Published online: 13 August 2019

\begin{abstract}
Silver (Ag) in various forms have recently gained broad interest and been revisited due to their promising antimicrobial effects. Here we report our study on the morphological dynamics of live bacteria when subjected to $\mathrm{Ag}^{+}$ions. Using time-lapse microscopy, we observed oscillations of celllength for a large fraction of bacteria exposed to $60 \mu \mathrm{M}$ of $\mathrm{Ag}^{+}$ions. In addition, we found that the responses of bacteria to $\mathrm{Ag}^{+}$ions were heterogeneous. We quantified the oscillations of cell-length with power spectral density, which appeared different from that of bacteria growing in the absence of $\mathrm{Ag}^{+}$ions. Furthermore, a model similar to the predator-prey argument was developed to understand the observed oscillations of cell-length upon exposure to $\mathrm{Ag}^{+}$ions. This model not only successfully produced the oscillations but also explained the observed heterogeneity in the bacterial responses to $\mathrm{Ag}^{+}$ions.
\end{abstract}

Due to the rising of antibiotic resistance of bacteria ${ }^{1-4}$, alternatives of commonly prescribed antibiotics have been gaining broad interest and attention in the past few years. Noble metals and their derivatives have been promising candidates, while silver ions $\left(\mathrm{Ag}^{+}\right)$and silver nanoparticles (AgNPs) are among the most well studied ${ }^{5-30}$. It has been extensively reported that $\mathrm{Ag}^{+}$ions and $\mathrm{AgNPs}$ can effectively suppress the growth of, and kill, bacteria $^{5-7,13-15,17,19,22,24,26,28-30}$, which might open new avenues to fighting against drug resistance of harmful microbes.

Although much effort has been made to investigate the antibiotic activity of $\mathrm{Ag}^{+}$ions and AgNPs, the temporal resolution of these studies is lacking, as pointed out by Durán et al. ${ }^{29}$. Few studies exist for how $\mathrm{Ag}^{+}$ions and AgNPs suppress the growth of, and kill, bacteria in real-time. In addition, whether bacteria are capable of developing resistance against Ag remains controversial ${ }^{6}$. While some claimed that it is difficult for bacteria to develop resistance against Ag due to Ag's multi-modal antimicrobial activities ${ }^{28,31}$, other studies suggested the opposite $^{32-34}$. For example, Graves et al. showed that Escherichia coli (E. coli) bacteria evolve rapidly and develop resistance against $\mathrm{AgNPs}^{32-34}$.

In an effort towards understanding Ag's antimicrobial activity and mechanism, we previously examined in depth the growth of bacteria in the presence of $\mathrm{Ag}^{+}$and AgNPs and found that the growth rate of the bacteria remained unaffected but the lag time of the bacterial growth was extended ${ }^{6}$. This observation led to a phenomenological model consisting of a "suppressed" state of bacteria caused by $\mathrm{Ag}^{+}$ions and AgNPs. In this "suppressed" state, the bacteria struggle and defend themselves from Ag-induced damages and stresses ${ }^{6}$. In this model, a fraction of the bacteria are able to fight through the damages and stresses caused by $\mathrm{Ag}^{+}$ions and AgNPs, going back to an "active" state and growing normally ${ }^{6}$. In contrast, another fraction of the bacteria are killed, entering a "dead" state ${ }^{6}$. Although this phenomenological model explains the experimental observations very well ${ }^{6}$, such battles between the bacteria and Ag-induced damages and stresses have not been directly visualized in real-time.

Here we report our study on the morphological dynamics of live bacteria when subjected to $\mathrm{Ag}^{+}$ions using time-lapse microscopy. We observed that a large fraction of bacteria exposed to $\mathrm{Ag}^{+}$ions exhibited oscillations in their cell-lengths (i.e., elongating and shrinking back and forth). In addition to the oscillatory bacteria, we found that the responses of bacteria to $\mathrm{Ag}^{+}$ions are heterogeneous: some bacteria shrink their lengths, while others grow and divide after struggling through the stresses. We also quantified the oscillations of the cell-length with power spectral density, which is different from that of bacteria growing in the absence of $\mathrm{Ag}^{+}$ions. Furthermore, we developed a model based on the predator-prey model for qualitatively understanding the observed oscillation of cell-length upon exposure to $\mathrm{Ag}^{+}$ions. This model not only successfully produced the cell oscillation but also explained the observed heterogeneity in the bacterial responses to $\mathrm{Ag}^{+}$ions.

\footnotetext{
${ }^{1}$ Department of Physics, University of Arkansas, Fayetteville, AR, 72701, USA. ${ }^{2}$ Department of Chemistry and Biochemistry, University of Arkansas, Fayetteville, AR, 72701, USA. ${ }^{3}$ Microelectronics-Photonics Graduate Program, University of Arkansas, Fayetteville, AR, 72701, USA. ${ }^{4}$ Cell and Molecular Biology Program, University of Arkansas, Fayetteville, AR, 72701, USA. Correspondence and requests for materials should be addressed to Y.W. (email: yongwang@uark.edu)
} 


\section{Results \\ Oscillation of cell-length and heterogeneous response of bacteria upon exposure to $\mathrm{Ag}^{+}$}

ions. Although it was reported previously that bacteria shrank their lengths when subjected to $\mathrm{Ag}^{+}$ions ${ }^{35}$, temporal resolution was lacking in the previous studies ${ }^{29}$. We exploited time-lapse imaging to examine the dynamics of bacterial morphology after treating the bacteria with $\mathrm{Ag}^{+}$ions (SI Movies M1 and M2). Most interestingly, we found that a large fraction of bacteria (24 out of 31 bacteria in SI Movie M1, or $~ 68 \%$ on average from replicated experiments) showed oscillations in their cell-length as a function of time. In other words, the lengths of bacteria increased and decreased back and forth during 12 hours in the presence of $\mathrm{Ag}^{+}$ions. In contrast, a negative control showed that the bacteria grew and divided normally in the absence of $\mathrm{Ag}^{+}$ions (SI Movie M3). To see the oscillations of cell-length in the presence of $\mathrm{Ag}^{+}$ions more clearly, four individual oscillating bacteria were cropped out (SI Movies M4-M7) and their lengths as functions of time (or frame number) were quantified using ImageJ, MicrobeJ and/or Oufti (Fig. 1A-D, respectively) $)^{36-39}$. The raw data from MicrobeJ and/or Oufti (gray curves in Fig. 1) for the cell-length have been smoothed by convolving with a Hanning window with a window size of 11 frames (blue curves in Fig. 1) ) $^{40,41}$. For each bacterium, eight frames at peaks/valleys in the lengthvs-time curves were shown (T1 to T8, Fig. 1), from which visual differences in the cell-length can be observed. We note that these oscillations lasted for at least 12 hours in our experiments (Fig. 1). The magnitude (i.e., maximum - minimum) of the oscillations ranged from $0.4 \mu \mathrm{m}$ to $1.5 \mu \mathrm{m}$, with a mean of $0.75 \pm 0.27 \mu \mathrm{m}$ (mean \pm standard deviation, sample size $=20$ ).

The observed oscillations of cell-length when subjecting bacteria to $\mathrm{Ag}^{+}$ions are not artifacts due to the following reasons. First, the observations of oscillatory cell-length were reproducible. We repeated the experiments five times on different days and reproduced that bacteria treated with $\mathrm{Ag}^{+}$ions exhibited oscillatory behavior. For example, SI Movie M2 was taken on a different day other than SI Movie M1. Second, the change in the cell size is unlike due to focusing/defocussing of the microscope, because an autofocus system was used during the time-lapse imaging of 12 hours. Third, we observed large heterogeneity in the bacterial responses to $\mathrm{Ag}^{+}$ions (Fig. 2A-D). For example, apart from the oscillatory bacteria, some cells in the same field of view showed shrinkage (Fig. 2A,B, SI Movies M8 and M9). Among all the replicated experiments, $31 \%$ of the bacteria eventually shrank. The shrinkage was previously reported although the dynamics was unknown ${ }^{35}$. Interestingly, $\sim 55 \%$ of the shrinking bacteria showed step-wise behaviors, an example of which was highlighted by the blue arrow in Fig. 2A. In addition to the shrinking bacteria, $\sim 7 \%$ of the bacteria grew and divided after oscillations (Fig. $2 \mathrm{C}$, SI Movie M10), indicating that these bacteria have won the battle and overcome the antimicrobial effects posed by $\mathrm{Ag}^{+}$ions. Furthermore, we observed that a small fraction $(\sim 2 \%)$ of the bacteria eventually exploded (Fig. $2 \mathrm{D}$ and SI Movie M11). The forth reason is that the oscillations of different bacteria were unsynchronized. An example is shown in SI Movie M12, where five bacteria were aligned well but the oscillations of these cells were independent to each other. Lastly, negative control experiments were performed with the same bacteria and microscope but in the absence of $\mathrm{Ag}^{+}$ions (SI Movie M3), from which we observed monotonic growth of bacteria. For example, $100 \%$ of the initial $\sim 120$ bacteria in SI Movie M3 grew and divided normally. Most ( $85 \%)$ of the quantified bacteria (sample size $=34$ ) showed nearly linear increase in their cell-lengths (Fig. 2E, SI Movie M13, and SI Fig. S1A-E), although lagging was observed for a fraction of bacteria ( 15\%, Fig. 2F, SI Movie M14). The average of the normalized cell-length $\left(\ell_{c} / \ell_{c 0}\right.$, where $\ell_{c 0}$ is the cell-length of a bacterium in frame 0$)$ for 16 bacteria with trajectories of at least 200 frames (including the lagging ones) was shown in SI Fig. S1F, clearly displaying the nearly linear growth of bacteria in the absence of $\mathrm{Ag}^{+}$ions, consistent with results previously reported in the literature ${ }^{42}$. Therefore, all the evidence suggests that the observed oscillations of cell-length are actual.

We quantified the heterogeneity of the responses of bacteria to $\mathrm{Ag}^{+}$ions by counting the number of bacteria in each category of responses. Out of the quantified 99 bacteria from replicated experiments, we observed that (1) $54 \%$ of the bacteria showed oscillations for 12 hours (i.e., no obvious growth or shrinkage at the end of the 12 hours), (2) $10 \%$ of the bacteria shrank after oscillations, (3) $21 \%$ of the bacteria shrank directly, (4) $7 \%$ of the bacteria grew and divided after oscillations or directly, (5) $2 \%$ of the bacteria exploded eventually, and (6) $6 \%$ of the bacteria stayed fairly constant. We speculate that the observed heterogeneity might result from (1) differences in the intrinsic sensitivity of the bacteria to $\mathrm{Ag}^{+}$treatment, (2) variances in the local concentrations of $\mathrm{Ag}^{+}$ions, and (3) differences in the rate of adaptation of bacteria to and/or resistance against $\mathrm{Ag}^{+}$ions and Ag-induced damages and stresses. However, further studies are needed to determine the underlying mechanism of the observed heterogeneity.

We asked whether there exist any characteristic frequencies/periods in the oscillations of cell-length. The answer is negative when looking at the cell-length curves (Fig. 1). In addition, it appears that the oscillatory patterns of different bacteria are different (Fig. 1), suggesting the absence of characteristic oscillatory frequencies. Furthermore, we examined the power spectral density (PSD) ${ }^{43}$ of the cell-length curves using the Welch method (with a Hanning window and a length of segment of 512 ${ }^{41,44}$. The averaged PSD from the four unsmoothed oscillatory cell-length curves (Fig. 1) is shown in Fig. 3A, where the error bars stand for the standard error of the mean (SEM). We observed that the PSD did not display any characteristic peak. Instead, it was similar to the response of a low-pass filter. The slope of the power-law regime in the log-log scale is close to -2 (red dashed line in Fig. 3A). We also examined the PSD for the negative controls (i.e., the growing bacteria in the absence of $\mathrm{Ag}^{+}$ ions, Fig. 2E,F) and found that the power-law exponent is close to -4 (green dashed curve in Fig. 3B), different from the oscillatory cell-length curves. In addition, the power-law regime shifted to lower frequencies compared to the oscillatory cell-length curves. Lastly, to further confirm the absence of characteristic frequency/period in the oscillations of cell-length, we manually identified peaks in the cell-length curves (Fig. 1) and calculated the time intervals $(\Delta T)$ between peaks. The histogram of $\Delta T$ did not show obvious peaks (Fig. 3C), indicating the absence of characteristic periods once again. To compare the manual results with the PSD, we looked at the 
(A)


(B)
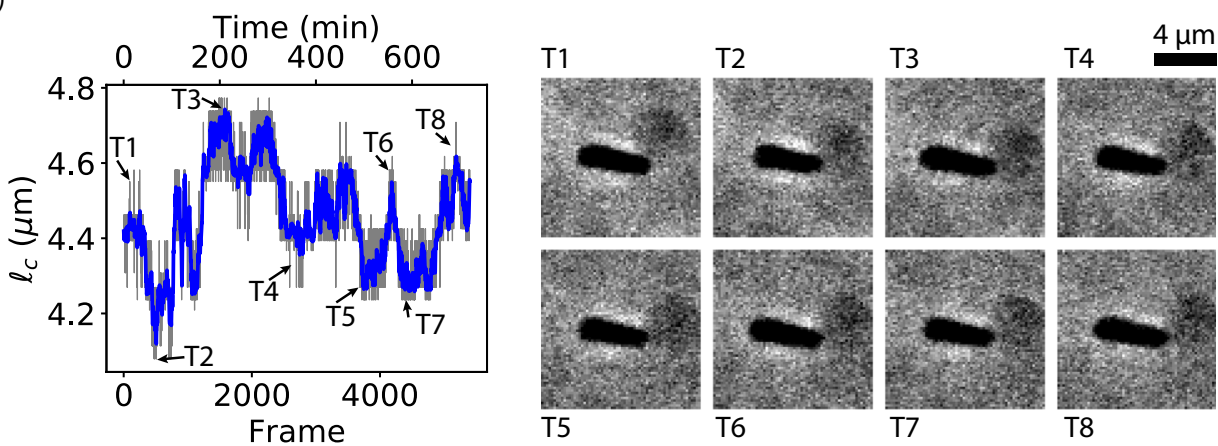

(C)
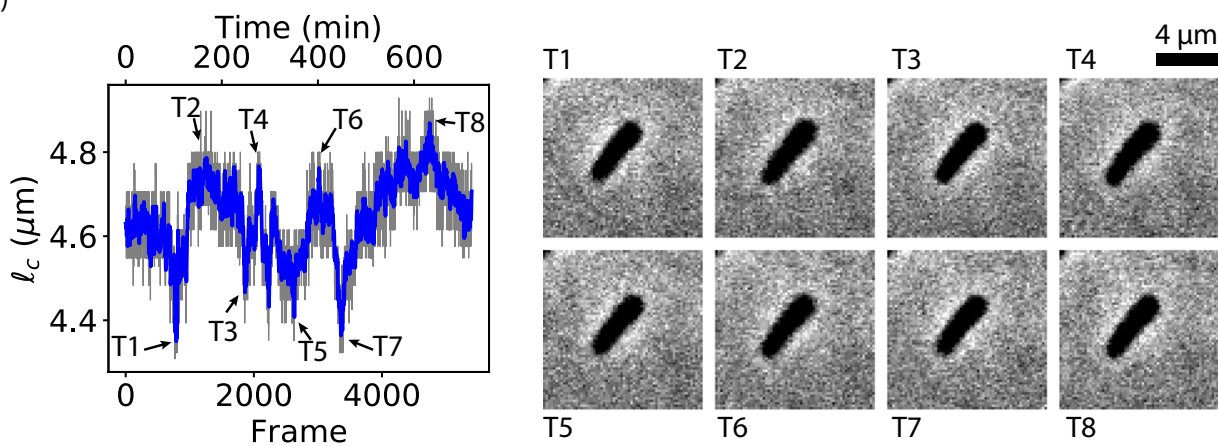

(D)
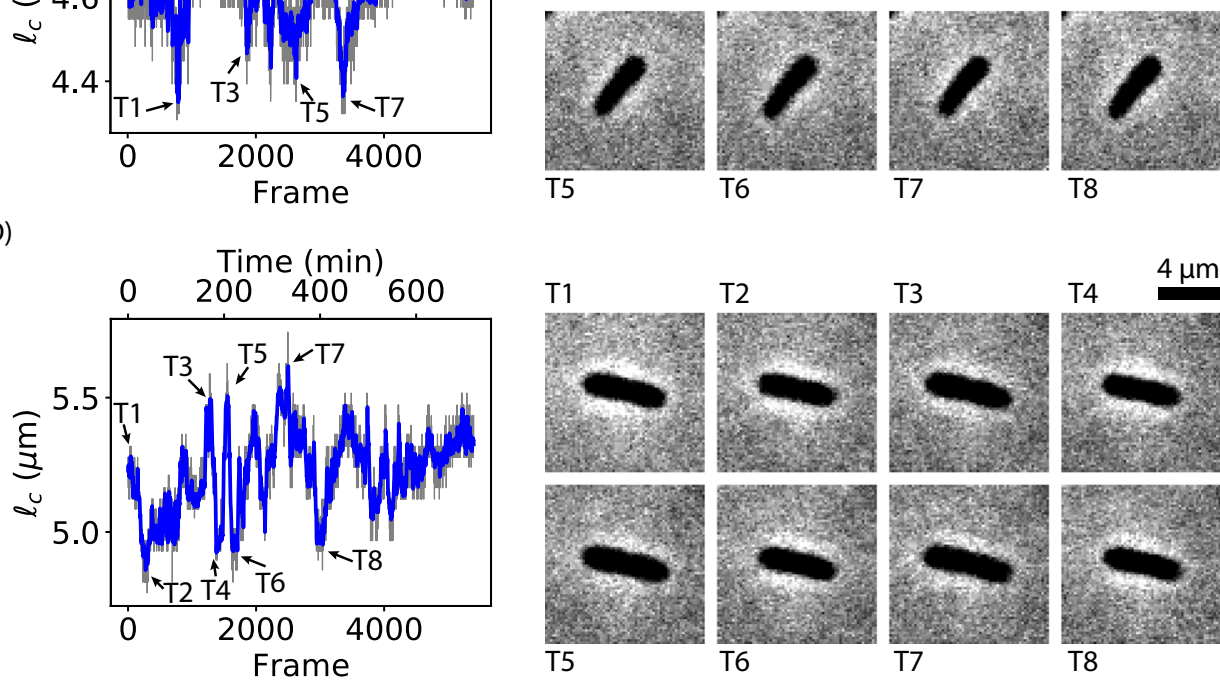

16

T7

T8
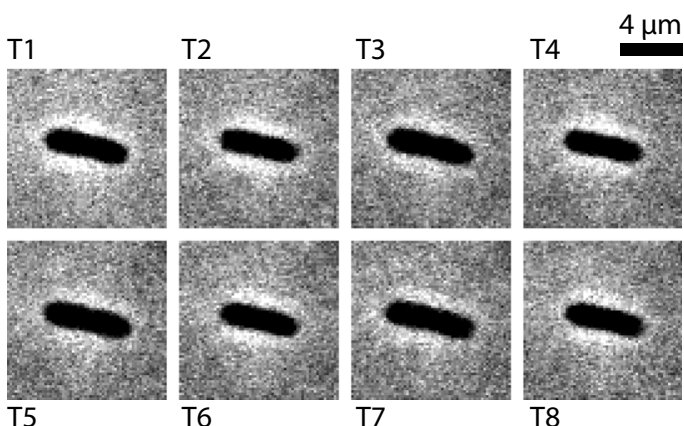

Figure 1. Oscillation in cell-length. (A-D) Cell-length as a function of frame number (time) from four examples of oscillatory bacteria in the presence of $\mathrm{Ag}^{+}$ions. Representative peaks and valleys in the fluctuations were labeled by arrows and numbered as T1, T2, ., and T8. Images of the bacteria in the frames $\left\{T_{i}\right\}$ are shown in the right panels, extracted from (A) SI Movie M4, (B) SI Movie M5, (C) SI Movie M6, and (D) SI Movie M7.

distribution of $1 / \Delta T$ (i.e., the "frequency"). Interestingly, a power-law with an exponent of -2 was observed around $10^{-3} \mathrm{~Hz}$ (Fig. 3D), consistent with power-law exponent from the PSD (Fig. 3A).

Predator-prey-like model for understanding the oscillations of cell-length. To understand the experimentally observed oscillations of cell-length after subjecting the bacteria to $\mathrm{Ag}^{+}$ions, we developed a model based on the predator-prey argument ${ }^{45,46}$. Briefly, we consider a system composed of nutrients $(N)$, positive growing components such as active proteins and other cellular products $(P)$, and damaging components such 
(A)



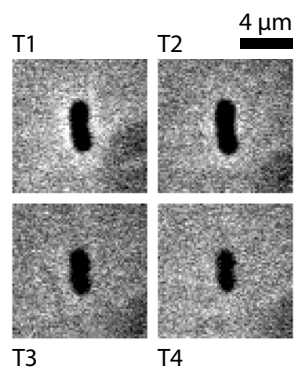

(B)

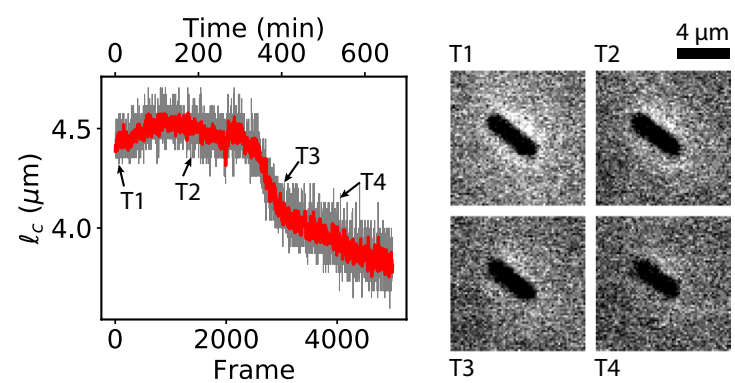

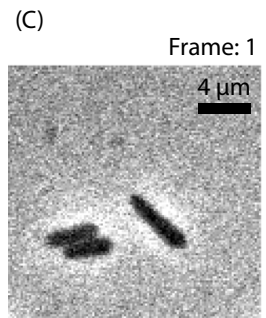
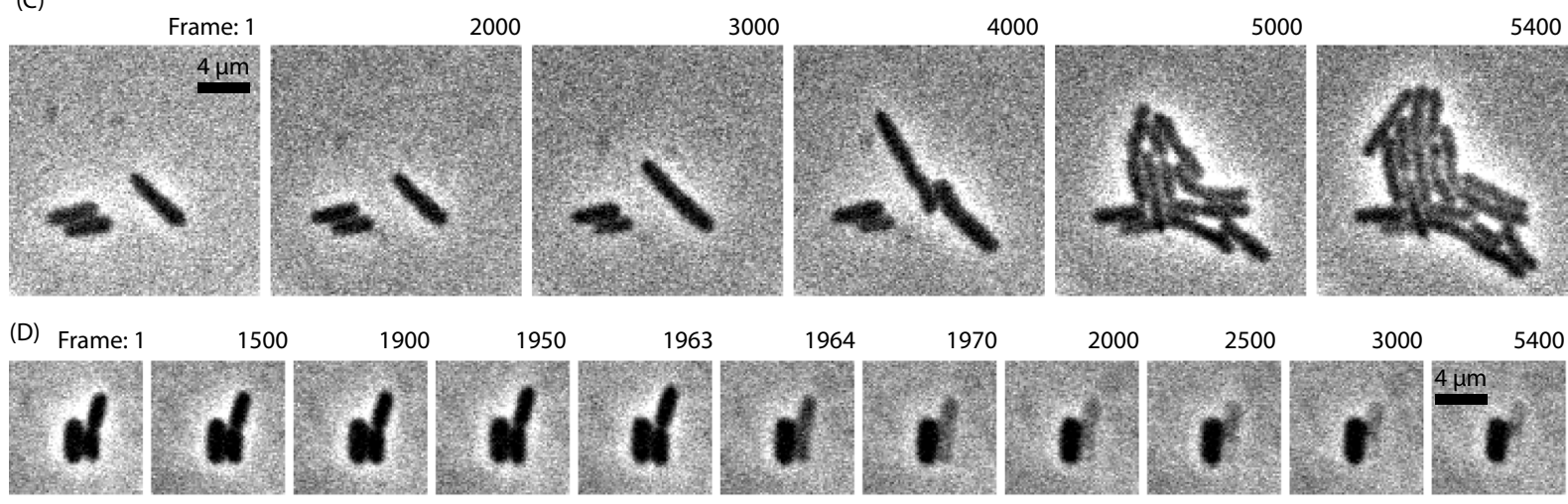

(E)

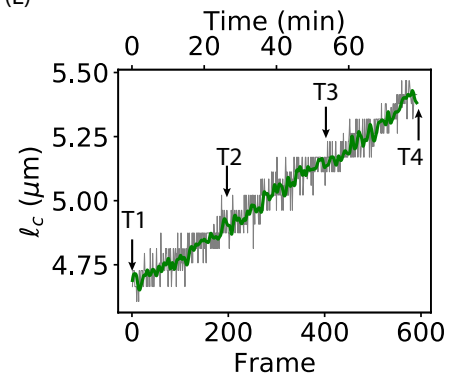

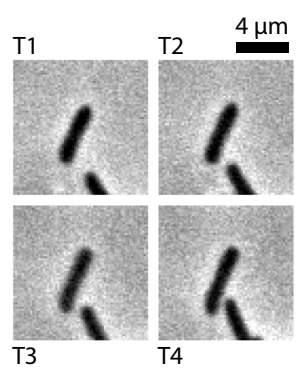

(F)
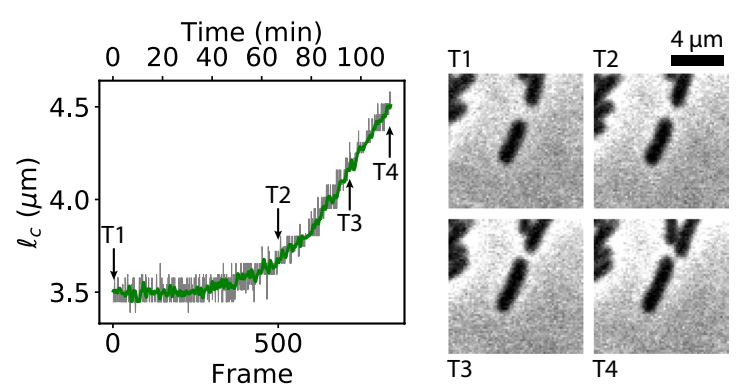

Figure 2. Heterogeneity of bacterial responses to $\mathrm{Ag}^{+}$treatment. (A,B) Cell-length as a function of frame number (time) for two examples of shrinking bacteria in the presence of $\mathrm{Ag}^{+}$ions. Representative frames were labeled by arrows and numbered as T1, T2, T3, and T4. Images of the bacteria in the frames $\left\{T_{i}\right\}$ are shown in the right panels, extracted from (A) SI Movie M8 and (B) SI Movie M9. (C) Frames of SI Movie M10 showing the growth of bacteria starting between Frame 2000 and 3000. (D) Frames of SI Movie M11 showing the burst of two cells happening between Frame 1950 and 2000. (E,F) Cell-length as a function of frame number (time) for two examples of growing bacteria in the absence of $\mathrm{Ag}^{+}$ions (i.e., negative control). Representative frames were labeled by arrows and numbered as T1, T2, T3, and T4. Images of the bacteria in the frames $\left\{T_{i}\right\}$ are shown in the right panels, extracted from (A) SI Movie M13 and (B) SI Movie M14.

as $\mathrm{Ag}^{+}$ions, protein/DNA damages, and reactive oxygen species $(D)$. The dynamics of this system is sketched in Fig. 4A, which shows the following four "reactions".

(1) The nutrients are taken into the bacteria from the growth medium with an intake rate of $r_{i}$,

$$
\varnothing \stackrel{r_{i}}{\rightarrow} N
$$

(2) The positive growing components are produced with a growth rate of $r_{g}$ by consuming nutrients,

$$
P+N \stackrel{r_{g}}{\rightarrow} 2 P
$$

(3) The positive growing components are damaged by the damaging components with a damaging rate of $r_{d}$,

$$
P+D \stackrel{r_{d}}{\rightarrow} 2 D
$$

(4) The damaging components are removed from the bacteria with an ousting rate of $r_{o}$, 
(A)

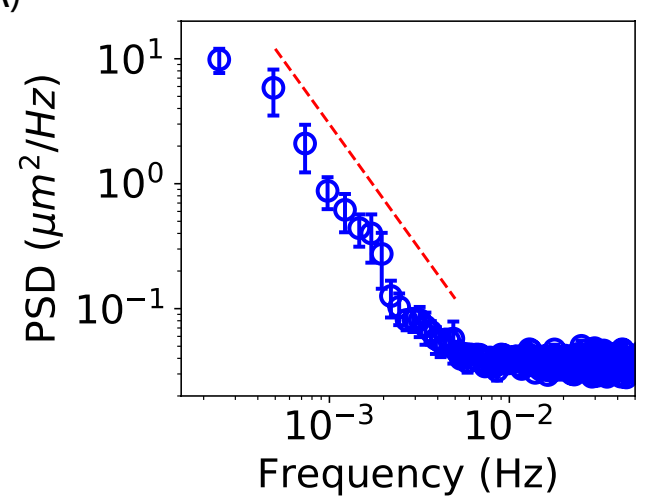

(C)

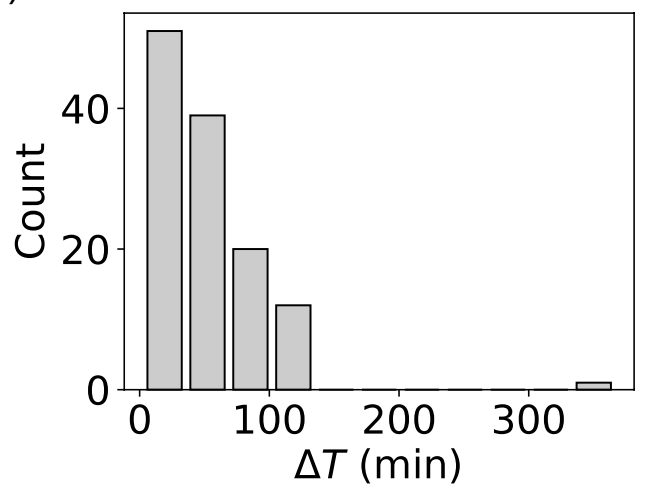

(B)

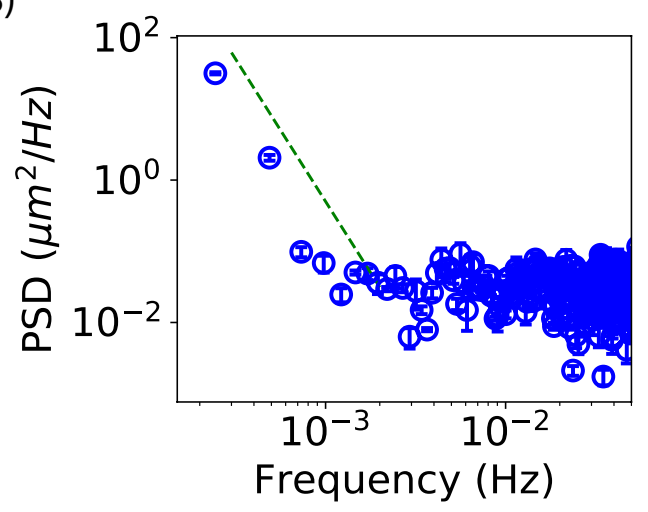

(D)

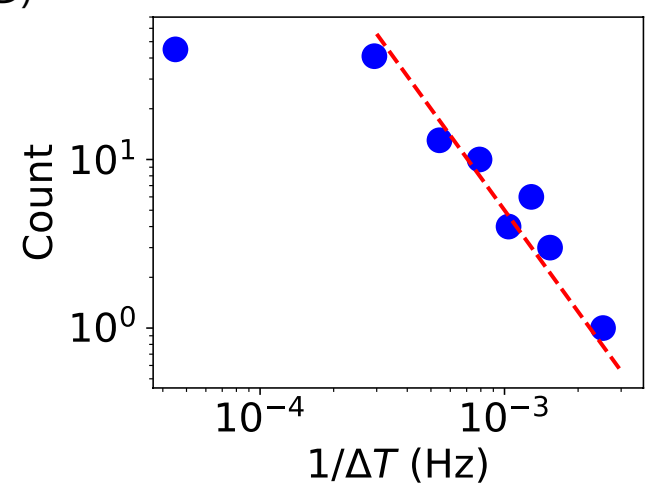

Figure 3. Quantification of cell-length curves. (A) Averaged PSD for the four unsmoothed oscillatory celllength curves in Fig. 1. The red dashed line indicates a slope of -2 in the log-log scale. (B) Averaged PSD for the two unsmoothed growing cell-length curves in Fig. 2E,F. The green dashed line indicates a slope of -4 in the $\log$-log scale. Error bars in $(\mathbf{A}, \mathbf{B})$ stand for standard error of the mean (SEM). (C) Histogram of the time interval $\Delta T$ between peaks (manually identified). (D) Histogram of the frequency $1 / \Delta T$ of peaks (manually identified). The red dashed line indicates a slope of -2 in the log-log scale.

$$
D \stackrel{r_{o}}{\rightarrow} \varnothing
$$

The first three "reactions" are straightforward, while the fourth one represents the battle of bacteria against $\mathrm{Ag}^{+}$ions and Ag-induced damages and stresses. We note that removal of the damaging components are possibly due to multiple pathways. First, $\mathrm{Ag}^{+}$ions could be pumped out of the bacteria by efflux pumps, which has been reported as a general mechanism of bacterial resistance against most toxic heavy metals $s^{34,47,48}$. A second pathway is degradation and repairing. Degradation of damaged proteins and repairing of damaged DNA are well-known means of quality control in bacteria ${ }^{49,50}$. Another possible way to remove the damaging components is that the bacteria might mutate and develop genotypic resistance against $\mathrm{Ag}^{32}$.

The corresponding differential equations for the number of the three species $(N, P$, and $D)$ in the system are

$$
\begin{gathered}
\frac{d N_{N}}{d t}=+r_{i}-r_{g} N_{P} N_{N} \\
\frac{d N_{P}}{d t}=+r_{g} N_{P} N_{N}-r_{d} N_{P} N_{D} \\
\frac{d N_{D}}{d t}=+r_{d} N_{P} N_{D}-r_{o} N_{D}
\end{gathered}
$$

The system was simulated using the Gillespie algorithm ${ }^{51,52}$. The simulations were run for a time duration of $T=4 \times 10^{4} \mathrm{~s}$, close to the duration of our experiments (12 hours, Fig. 1 and 2A-D). The initial conditions used for the simulations were $N_{N 0}=100$ (i.e., bacteria have a nutrient reservoir at the time of $\mathrm{Ag}^{+}$treatment), $N_{P 0}=100$ (i.e., bacteria are not killed immediately by $\mathrm{Ag}^{+}$ions and have remaining positive growing component), and $N_{D 0}=100$ (i.e., bacteria are partially damaged upon exposure to $\mathrm{Ag}^{+}$ions). To compare the simulations with our measurements, we assumed that the cell length of bacteria is proportional to the difference between the positive 
(A)

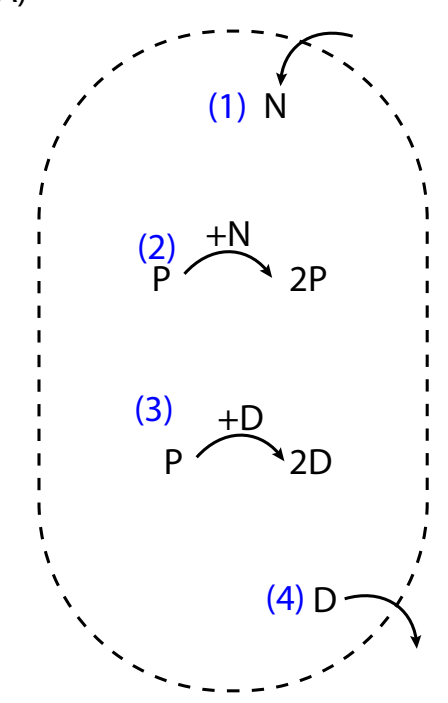

(B)

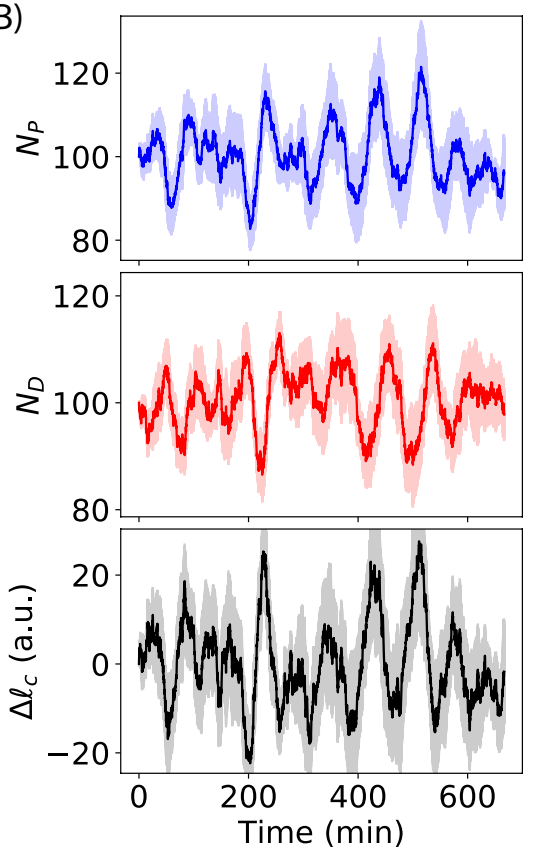

(C)
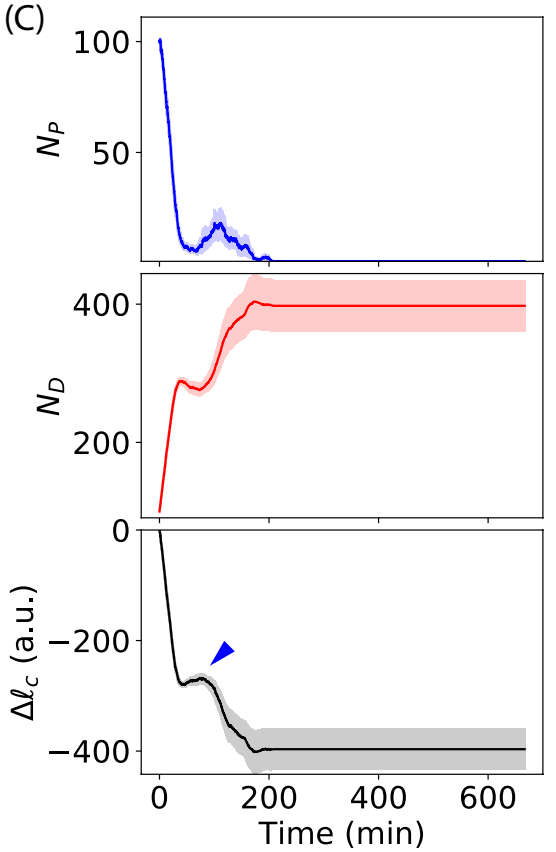

(D)


(E)

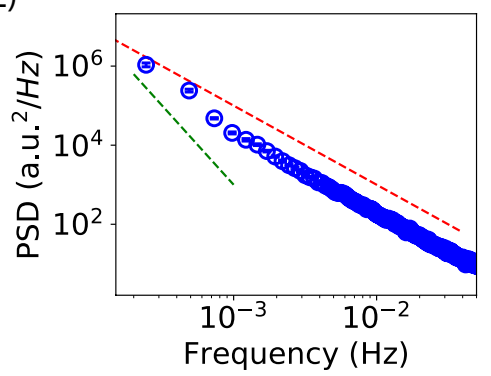

(F)



Figure 4. Predator-prey-like model. (A) Illustration of the components and dynamics of the system in our model. The "reactions" (1)-(4) in the system are described in the text. (B) Simulated oscillation of cell-length with simulation parameters $\left(r_{i}=0.1 \mathrm{~s}^{-1}, r_{g}=10^{-5} \mathrm{~s}^{-1}, r_{d}=10^{-5} \mathrm{~s}^{-1}\right.$, and $\left.r_{o}=10^{-3} \mathrm{~s}^{-1}\right)$ and initial conditions $\left(N_{N 0}=100, N_{P 0}=100\right.$, and $\left.N_{D 0}=100\right)$. (C) Simulated cell shrinkage with the same initial conditions and parameters as in (B) except $r_{o}=10^{-4} \mathrm{~s}^{-1}$. (D) Simulated cell growth with the same initial conditions and parameters as in (B) except $r_{o}=3 \times 10^{-3} \mathrm{~s}^{-1}$. The dark lines in (B-D) are averages of 10 simulations, while the light areas stand for the standard errors of the means. (E,F) Power spectral densities of simulated cell-length curves with the same initial conditions and parameters as in $(\mathbf{B}, \mathbf{D})$. The red dashed line indicates a slope of -2 , while the green dashed line indicates a slope of -4 in the log-log scale.

growing components $P$ and the damaging components $D$, i.e., $\ell_{c} \propto N_{P}-N_{D}$. Then the change in the cell length is indicated by $\Delta \ell_{c} \propto \Delta N_{P}-\Delta N_{D}$. With $N_{P 0}=N_{D 0}=100$, it is simplified to $\Delta \ell_{c} \propto N_{P}-N_{D}$.

Oscillations of $\Delta \ell_{c}$ (and $\ell_{c}$ ) were observed in simulations with appropriate parameters. The dynamics of $N_{P}$, $N_{D}$ and $\Delta \ell_{c}$ from 10 simulations with $r_{i}=0.1 \mathrm{~s}^{-1}, r_{g}=10^{-5} \mathrm{~s}^{-1}, r_{d}=10^{-5} \mathrm{~s}^{-1}$, and $r_{o}=10^{-3} \mathrm{~s}^{-1}$ are shown in Fig. 4B, where the dark lines represent the averages of the repeated simulations and the lighter areas show the standard 
(A)

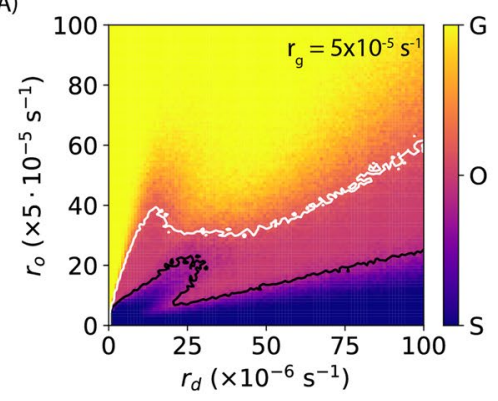

(D)

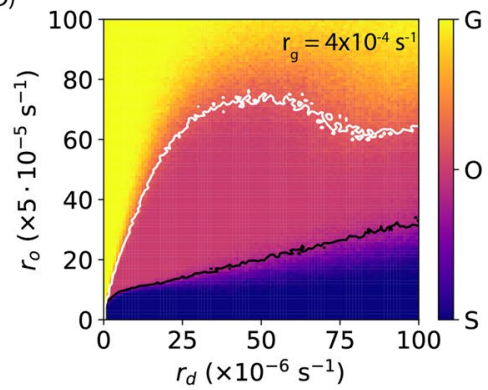

(B)

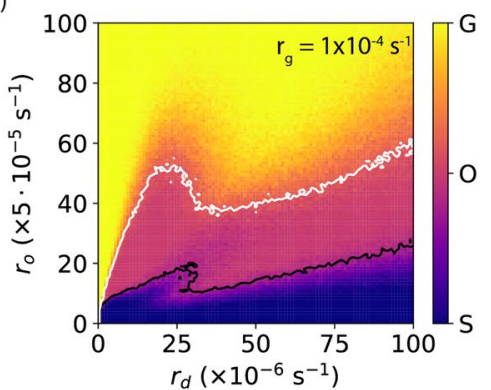

(E)

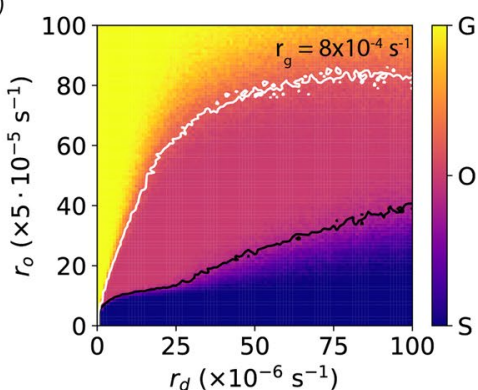

(C)

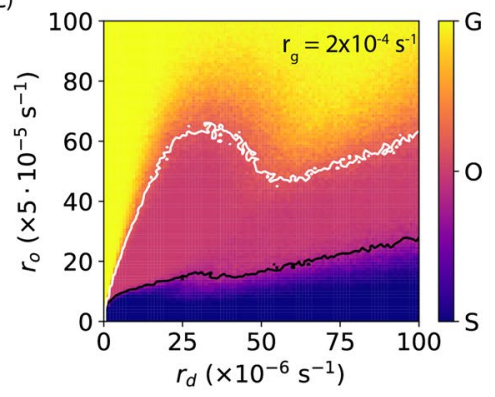

$(\mathrm{F})$

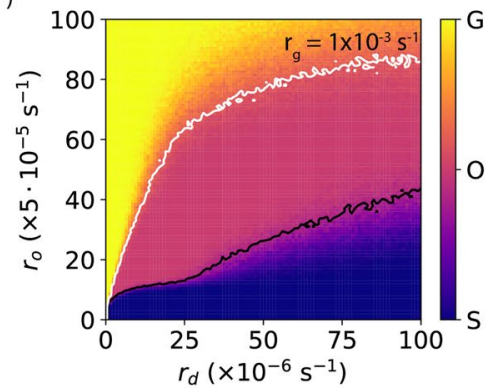

Figure 5. Phase diagrams (the ousting rate $r_{o} v s$. the damaging rate $r_{d}$ ) of our model at different growth rates, (A) $r_{g}=5 \times 10^{-5} \mathrm{~s}^{-1}$, (B) $r_{g}=1 \times 10^{-4} \mathrm{~s}^{-1}$, (C) $r_{g}=2 \times 10^{-4} \mathrm{~s}^{-1}$, (D) $r_{g}=4 \times 10^{-4} \mathrm{~s}^{-1},(\mathrm{E}) r_{g}=8 \times 10^{-4} \mathrm{~s}^{-1}$, and $(\mathbf{F}) r_{g}=1 \times 10^{-3} \mathrm{~s}^{-1}$. The white and black curves in $(\mathbf{A}-\mathbf{F})$ correspond to contour levels of 1.2 and 0.8 , respectively. The legends on the color bars read as the following: $\mathrm{G}=$ growth, $\mathrm{O}=$ oscillation, and $\mathrm{S}=$ shrinkage.

errors of the means (SEM). Oscillations of $N_{P}$ and $N_{D}$ were observed, similar to the populations of predators and preys in the predator-prey models ${ }^{46}$. Oscillatory fluctuations were also observed for the change in the cell-length, $\Delta \ell_{c}$ (Fig. 4B). In addition, this predator-prey-like model also predicts shrinkage and growth of the bacteria, if different parameters are chosen. If the bacteria cannot remove $\mathrm{Ag}^{+}$ions and $\mathrm{Ag}$-induced damages quickly enough (i.e., lower ousting rate $r_{o}$ ), the bacteria shrink their lengths. For example, when using $r_{o}=10^{-4} s^{-1}$ (but keeping the other parameters the same as those in Fig. 4B), bacterial shrinkage was observed (Fig. 4C). Interestingly, this model predicted that decreases in the cell-length might be step-wise (blue arrow for $\Delta \ell_{c}$ in Fig. 4C), which was observed experimentally (blue arrow in Fig. 2A). In contrast, if the bacteria are capable of removing $\mathrm{Ag}^{+}$ions and Ag-induced damages more quickly (i.e., higher ousting rate $r_{o}$ ), cell growth was observed (Fig. 4D where $r_{o}=3 \times 10^{-3} \mathrm{~s}^{-1}$ ).

Furthermore, we examined the power spectral density (PSD) of the simulated oscillatory cell-length curves. For this study, 10 simulations were ran for $T=4 \times 10^{5} \mathrm{~s}$ with the parameters used in Fig. $4 \mathrm{~B}$. The averaged cell-length curve (represented by $\ell_{c} \propto N_{P}-N_{D}$ ) was computed for estimating the PSD by the Welch method

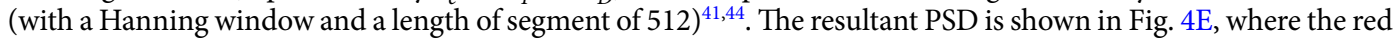
and green dashed line indicate slopes of -2 and -4 , respectively, in the log-log scale. We note that direct comparison for the magnitude of the PSD between the simulations and the experiments are not appropriate as the simulated cell-lengths were not actual lengths due to the unknown proportionality constant. Instead, we focused on comparing the slopes in the PSD data. We observed that the PSD of the simulated oscillating cell-length curves has a slope of -2 , consistent with the experimental measurements (Fig. 3A). On the other hand, we found that a flat region at higher frequencies in the experimental result (Fig. 3A) was not present in the PSD of the simulated curves (Fig. 4E). A possible reason is that the flat region in the experimental measurements was due to experimental noises. In contrast, the PSD for simulated growing bacteria (Fig. 4F, with the same parameters as used in Fig. $4 \mathrm{C}$ but $T=4 \times 10^{5} \mathrm{~s}$ ) showed a kink around $10^{-3} \mathrm{~Hz}$. The slope in the PSD for growing bacteria was -4 in the log-log scale at low frequencies $\left(<10^{-3} \mathrm{~Hz}\right)$, consistent with the experimental result (Fig. $\left.3 \mathrm{~B}\right)$.

Lastly, we examined the phase diagrams of our model by varying the three rates, $r_{g} \in\left[0,10^{-4}\right] \mathrm{s}^{-1}, r_{d} \in\left[0,10^{-4}\right]$ $\mathrm{s}^{-1}$, and $r_{o} \in\left[0,5 \times 10^{-3}\right] \mathrm{s}^{-1}$, while keeping the initial conditions and the intake rate constant $\left(N_{N 0}=N_{P 0}=N_{D 0}=100\right.$ and $\left.r_{i}=0.1 \mathrm{~s}^{-1}\right)$. For each set of parameters $\left(r_{g}, r_{d}, r_{o}\right), 100$ simulations were run for $T=4 \times 10^{4} \mathrm{~s}$. For each simulation, the type of the bacterial response was determined by comparing the difference between the end-point values of $N_{P}$ and $N_{D}$ with a threshold $N_{t h}$ : growth if $\left(N_{P}-N_{D}\right)>+N_{t h}$, oscillation if $-N_{t h} \leq\left(N_{P}-N_{D}\right) \leq+N_{t h}$, and shrinkage if $\left(N_{P}-N_{D}\right)<-N_{t h}$. Then the probability of the three types of responses $\left(p_{g}, p_{o}, p_{s}\right)$ were estimated from the 100 simulations. To report different types of responses in the same phase diagrams, we computed the weighted averages, $\bar{p}=G \times p_{g}+O \times p_{o}+S \times p_{s}$, where $G=2, O=1$, and $S=0$. If the weighted average is close to $O=1$, the most probable response would be oscillation. The phase diagrams $\left(r_{o}\right.$ vs. $r_{d}$ ) of our model at different $r_{g}$ values with $N_{t h}=150$ are shown in Fig. 5, where the white and black lines represent the contour levels of 1.2 and 0.8 (close to $O=1$ ), respectively. As seen from the phase diagrams (Fig. 5), at low ousting rates $\left(r_{o}\right)$, it is most likely that bacteria would shrink for most damaging rates $\left(r_{d}\right)$. With a given damaging rate $\left(r_{d}\right)$, the most probable response of the bacteria changes from shrinkage to oscillation and then to growth, as 
the ousting rate $r_{o}$ increases. This result is expected because a higher ousting rate corresponds to higher resistance of bacteria against $\mathrm{Ag}$. It is noted that, although the phase diagrams were qualitatively similar, quantitative differences were observed for different growth rates $r_{g}$ (Fig. 5), suggesting that $r_{g}$ also plays a role in the bacterial response in our model. We also note that the phase diagrams with different thresholds gave similar results as shown in SI Fig. S2 where $N_{t h}=100$ or $N_{t h}=200$.

\section{Discussions}

In this study, we used time-lapse microscopy to examine the morphological dynamics of live E. coli bacteria when subjected to $\mathrm{Ag}^{+}$ions at $60 \mu \mathrm{M}$. We observed that approximately $68 \%$ of the bacteria exposed to $\mathrm{Ag}^{+}$ions elongated and shrank back and forth, clearly displaying oscillatory behaviors. In addition, we found that the bacterial responses to $\mathrm{Ag}^{+}$ions are heterogeneous: in addition to the oscillating ones, $\sim 21 \%$ of the bacteria simply shrank their lengths, while $\sim 7 \%$ of them won the battle against $\mathrm{Ag}^{+}$ions and eventually grew and reproduced. We quantified the oscillations of the cell-length by examining the power spectral density (PSD), which showed a power of -2 . In contrast, the PSD of growing cells in the absence of $\mathrm{Ag}^{+}$ions displayed a power of -4 . Furthermore, a predator-prey-like model was developed to qualitatively understand the observed oscillation of the cell-length upon exposure to $\mathrm{Ag}^{+}$ions. This model not only produced the cell oscillations but also explained the observed heterogeneity in the bacterial responses to $\mathrm{Ag}^{+}$ions. The PSDs predicted by our model were partially consistent with the experimental results. Lastly, we examined the phase diagrams of our model.

The current study provides an experimental explanation for our previous observations that the lag time of the bacterial growth was significantly elongated in the presence of $\mathrm{Ag}^{+}$ions at moderate concentrations ${ }^{6}$. The oscillations of the cell-length indicate that the bacteria fight against the stresses and/or other negative effects caused by $\mathrm{Ag}^{+}$ions, and that bacteria attempt to adapt to the $\mathrm{Ag}^{+}$environment during the elongated lag time. In addition, the current results suggest that the oscillatory stage of the bacteria corresponds to the "suppressed" state of bacteria in our previous phenomenological "SAD" model ${ }^{6}$, or the active but nonculturable (ABNC) state observed by Jung et al..$^{53}$. In addition, our data showed that a fraction of the bacteria are able to grow again after several cycles of oscillations, supporting the assumed transition from the "suppressed" state to the "active" state in our previous "SAD" model'.

Oscillations play important roles in many dynamic cellular processes in both eukaryotes and prokaryotes ${ }^{54}$. For example, Min proteins oscillate in bacteria from one pole to the other, helping the bacteria to divide at appropriate time and place ${ }^{5-56}$. In addition, Tanouchi et al. observed that a subpopulation of bacteria might exhibit transient oscillations in cell size in long time scales with periods of several generations ${ }^{57}$. However, to our knowledge, oscillations of the cell-length of individual bacteria in short time scales were observed for the first time. An interesting question is whether and how these oscillations share common features and/or general underlying principles.

The assumption that $\mathrm{Ag}^{+}$ions and $\mathrm{Ag}$-induced damages are removed from the bacteria is essential in our model (Fig. 4A). This assumption implies that the bacteria possess certain resistance against Ag. However, it is worthwhile to emphasize that this assumption has no implication on whether the bacteria mutate and develop Ag-resistances. It is well known that endogenous resistance of bacteria to most toxic heavy metal is based on energy-dependent efflux of ions by membrane proteins that function as ATPases or chemiosmotic antiporters ${ }^{47,48}$. For example, Franke et al. reported that the cus determinant (cusS and cusCFBA) on the chromosome of E. coli (previously known as the ybcZ-ylcA ylcBCD-ybdE region) is responsible for the bacterial resistance to $\mathrm{Cu}$ and $\mathrm{Ag}$, because deletion of these genes resulted in sensitive mutants than the wild type ${ }^{58}$. A later systematic study by Ivask et al. suggested that the several genes in the cus determinant were among the 35 common E. coli mutants that were sensitive to $\mathrm{Ag}^{+}$ions and $\mathrm{AgNPs}^{30}$. In addition, outer membrane proteins (e.g., ompR, ompC, ompF, and ompA) have also been shown to contribute to the bacterial resistance against Ag; these proteins are essential for the formation of pores to allow passive diffusion of small molecules across the outer membrane ${ }^{59,60}$. Due to their importance in removing $\mathrm{Ag}^{+}$ions, these efflux pumps could be promising candidates accounting for the molecular mechanism of the observed oscillations of cell-length. On the other hand, our model does not exclude the possibility of development of further resistance of bacteria against $\mathrm{Ag}^{+}$ions, which have been observed in previous studies. For example, mutations in $o m p R$ and $c u s S$ resulted in more Ag-resistant E. coli strains ${ }^{32,60}$. Mutations in other genes might also lead to greater fitness than the wild type in $\mathrm{Ag}$-containing environments ${ }^{32}$. It is noted that previous studies showed that mutations associated with Ag-resistance accumulated before 100 generations after Ag-treatment $(>15 \text { days })^{32}$; however, it is unclear whether mutations were present in our experiments, which lasted for only 12 hours. Future experiments with morbidostats ${ }^{61,62}$ would help to address these questions.

The phase diagrams of our model suggested that the response of bacteria to $\mathrm{Ag}^{+}$ions relies on the relation between the ousting rate $r_{o}$ and the damaging rate $r_{d}$. Our model suggests that, at a given concentration of $\mathrm{Ag}^{+}$ ions (corresponding to a given damaging rate $r_{d}$ ), the ability of the bacteria to remove $\mathrm{Ag}^{+}$ions and $\mathrm{Ag}$-induced damages determines the fate of the bacteria. Therefore, our model predicts that deletions of the efflux pumps and pores (i.e., cusCFBA and $o m p C F$ ) would result in lower ousting rates $r_{o}$ and lead to more sensitive and vulnerable strains compared to the wild type. This prediction is consistent with experimental results previously reported in the literature ${ }^{30,58}$. In addition, our model predicts that mutations in the cus and omp systems that result in a higher ousting rate of $\mathrm{Ag}^{+}$would provide the bacteria stronger resistance, which could be experimentally tested using mutants in future studies.

Lastly, the observed battles between bacteria and $\mathrm{Ag}^{+}$ions and $\mathrm{Ag}$-induced damages/stresses suggest that care must be taken with regards to using Ag as antimicrobial agents, and unintentional exposure of microbes to Ag should be minimized. 


\section{Materials and Methods}

Bacterial strain and growth. The E. coli strain used in this study is JW1225 of the Keio collection ${ }^{59}$ (purchased from the Yale E. coli Genetic Stock Center) transformed with a plasmid encoding hns-meos fusion gene $^{63}$. The resultant strain (named K12 $\Delta$ hns/pHNS-mEos3.2) expresses H-NS proteins fused to mEos3.2 photo-switchable fluorescent proteins ${ }^{63,64}$ and has kanamycin and chloramphenicol resistance ${ }^{63,65}$. This strain has been used in our other studies ${ }^{65}$, including several studies on the antibiotic activities of $\mathrm{Ag}^{+}$ions and $\mathrm{AgNPs}^{66}$.

The bacteria were grown at $37^{\circ} \mathrm{C}$ overnight in Luria broth (LB) medium supplemented with kanamycin and chloramphenicol. On the second day, the overnight culture was diluted by 50 to 100 times into fresh medium so that the OD 600 was 0.05 . The fresh cultures were again grown at $37^{\circ} \mathrm{C}$ until the OD 600 reached $\sim 0.3$, followed by adding $\mathrm{Ag}^{+}$ions into the culture at a final concentration of $60 \mu \mathrm{M}$. Then $10 \mu \mathrm{L}$ of the bacteria were transferred to a $5 \mathrm{~mm} \times 5 \mathrm{~mm}$ agarose pad ( $1 \%$ in the growth medium supplemented with $60 \mu \mathrm{M} \mathrm{Ag}$ ions in the form of $\mathrm{AgNO}_{3}$ solutions). For negative controls, $\mathrm{Ag}^{+}$were omitted in both the liquid medium and the agarose pad. The agarose pad with bacteria was flipped and attached to a clean coverslip (cleaned with sonication in detergent, $1 \mathrm{M}$ $\mathrm{NaOH}, 100 \%$ ethanol, and ultra-pure water sequentially). A chamber was then constructed by sandwiching a rubber o-ring between the coverslip and a microscope slide. The chamber was sealed using epoxy glue and then mounted for time-lapse imaging.

Time-lapse microscopy. Time-lapse imaging experiments were carried out at room temperature on an Olympus IX-73 inverted microscope in the phase contrast mode equipped with an Olympus 100X N.A. $=1.25$ objective and an EMCCD (Andor Technology). The effective pixel size of acquired images was $160 \mathrm{~nm}$. The microscope and data acquisition were controlled by Micro-Manager ${ }^{67}$. A CRISP autofocus system (Applied Scientific Instrumentation, USA) was used to keep the sample focused during the time-lapse imaging. For the acquisition of the time-lapse movies, the exposure time for each frame was $30 \mathrm{~ms}$, and the time interval between frames was $8 \mathrm{~s}$.

Quantification of cell-length from time-lapse movies. The acquired time-lapse movies were corrected for $\mathrm{x} / \mathrm{y}$ drift by cross-correlation using the scikit-image python module ${ }^{68,69}$ and analyzed in Image ${ }^{36,37}$. First, the movies were inverted, followed by removing background using the rolling ball method (with a radius of 10 pixels $)^{70}$. After smoothing, the images were inverted back, followed by cropping out movies for individual cells with ImageJ. For the movies of individual cells, MicrobeJ (an ImageJ plugin) and/or Oufti were applied to obtain the cell-length as a function of frame number ${ }^{38,39}$. The default algorithm (i.e., modified IsoData) was used for thresholding in MicrobeJ, while the smoothed option was turned on for detecting the bacteria edges ${ }^{38}$. The cell-lengths were outputted after running MicrobeJ/Oufti on the movies of individual cells.

\section{References}

1. Marchaim, D. et al. Outbreak of colistin-resistant, carbapenem-resistant Klebsiella pneumoniae in Metropolitan Detroit, Michigan. Antimicrob. Agents Chemother. 55, 593-599, https://doi.org/10.1128/AAC.01020-10 (2011).

2. Papp-Wallace, K. M., Endimiani, A., Taracila, M. A. \& Bonomo, R. A. Carbapenems: Past, present, and future. Antimicrob. Agents Chemother. 55, 4943-60, https://doi.org/10.1128/AAC.00296-11 (2011).

3. Perez, F. \& Van Duin, D. Carbapenem-resistant enterobacteriaceae: A menace to our most vulnerable patients. Cleve. Clin. J. Med. 80, 225-233, https://doi.org/10.3949/ccjm.80a.12182 (2013).

4. Sievert, D. M. et al. Antimicrobial-resistant pathogens associated with healthcare-associated infections: Summary of data reported to the National Healthcare Safety Network at the Centers for Disease Control and Prevention, 2009-2010. Infect. Control. Hosp. Epidemiol. 34, 1-14, https://doi.org/10.1086/668770 (2013).

5. Agnihotri, S., Mukherji, S. \& Mukherji, S. Size-controlled silver nanoparticles synthesized over the range 5-100 nm using the same protocol and their antibacterial efficacy. RSC Adv 4, 3974-3983, https://doi.org/10.1039/C3RA44507K (2014).

6. Haque, M. A. et al. An experiment-based model quantifying antimicrobial activity of silver nanoparticles on Escherichia coli. RSC Adv. 7, 56173-56182, https://doi.org/10.1039/C7RA10495B (2017).

7. Bao, H. et al. New toxicity mechanism of silver nanoparticles: Promoting apoptosis and inhibiting proliferation. PLoS One 10, 1-10, https://doi.org/10.1371/journal.pone.0122535 (2015).

8. Bresee, J., Maier, K. E., Boncella, A. E., Melander, C. \& Feldheim, D. L. Growth inhibition of staphylococcus aureus by mixed monolayer gold nanoparticles. Small 7, 2027-2031, https://doi.org/10.1002/smll.201100420 (2011).

9. Chatterjee, A. K., Chakraborty, R. \& Basu, T. Mechanism of antibacterial activity of copper nanoparticles. Nanotechnol. 25, 135101-135101, https://doi.org/10.1088/0957-4484/25/13/135101 (2014).

10. Chowdhury, M. N. K., Beg, M. D. H., Khan, M. R. \& Mina, M. F. Synthesis of copper nanoparticles and their antimicrobial performances in natural fibres. Mater. Lett. 98, 26-29, https://doi.org/10.1016/j.matlet.2013.02.024 (2013).

11. Cui, Y. et al. The molecular mechanism of action of bactericidal gold nanoparticles on Escherichia coli. Biomater. 33, 2327-2333, https://doi.org/10.1016/j.biomaterials.2011.11.057 (2012).

12. Fukuoka, T. et al. Application of gold nanoparticle self-assemblies to unclonable anti-counterfeiting technology. In 2015 International Conference on Electronic Packaging and iMAPS All Asia Conference (ICEP-IAAC), 432-435, https://doi.org/10.1109/ ICEP-IAAC.2015.7111051 (IEEE, 2015).

13. Geethalakshmi, R. \& Sarada, D. V. L. Characterization and antimicrobial activity of gold and silver nanoparticles synthesized using saponin isolated from Trianthema decandra L. Ind. Crop. Prod. 51, 107-115, https://doi.org/10.1016/j.indcrop.2013.08.055 (2013).

14. Kim, J. S. et al. Antimicrobial effects of silver nanoparticles. Nanomedicine Nanotechnol. Biol. Med. 3, 95-101, https://doi. org/10.1016/j.nano.2006.12.001 (2007).

15. Le Ouay, B. \& Stellacci, F. Antibacterial activity of silver nanoparticles: A surface science insight. Nano Today 10, 339-354, https:// doi.org/10.1016/j.nantod.2015.04.002 (2015).

16. Li, X. et al. Functional Gold Nanoparticles as Potent Antimicrobial Agents against Multi-Drug-Resistant Bacteria. ACS Nano 8, 10682-10686, https://doi.org/10.1021/nn5042625 (2014).

17. Maiti, S., Krishnan, D., Barman, G., Ghosh, S. K. \& Laha, J. K. Antimicrobial activities of silver nanoparticles synthesized from Lycopersicon esculentum extract. J. Anal. Sci. Technol. 5, 40-40, https://doi.org/10.1186/s40543-014-0040-3 (2014).

18. Meeker, D. et al. Synergistic Photothermal and Antibiotic Killing of Biofilm-associated Staphylococcus aureus using Targeted, Antibiotic-loaded Gold Nanoconstructs. ACS Infect. Dis. acsinfecdis.5b00117-acsinfecdis.5b00117, https://doi.org/10.1021/ acsinfecdis.5b00117 (2016). 
19. Pal, S., Tak, Y. K. \& Song, J. M. Does the Antibacterial Activity of Silver Nanoparticles Depend on the Shape of the Nanoparticle? A Study of the Gram-Negative Bacterium Escherichia coli. Appl. Environ. Microbiol. 73, 1712-1720, https://doi.org/10.1128/ AEM.02218-06 (2007).

20. Raffi, M. et al. Investigations into the antibacterial behavior of copper nanoparticles against Escherichia coli. Ann. Microbiol. 60, 75-80, https://doi.org/10.1007/s13213-010-0015-6 (2010).

21. Ramyadevi, J., Jeyasubramanian, K., Marikani, A., Rajakumar, G. \& Rahuman, A. A. Synthesis and antimicrobial activity of copper nanoparticles. Mater. Lett. 71, 114-116, https://doi.org/10.1016/j.matlet.2011.12.055 (2012).

22. Ruparelia, J. P., Chatterjee, A. K., Duttagupta, S. P. \& Mukherji, S. Strain specificity in antimicrobial activity of silver and copper nanoparticles. Acta Biomater. 4, 707-716, https://doi.org/10.1016/j.actbio.2007.11.006 (2008).

23. Shaalan, M., Saleh, M., El-Mahdy, M. \& El-Matbouli, M. Recent progress in applications of nanoparticles in fish medicine: A review. Nanomedicine Nanotechnol. Biol. Med. 12, 701-710, https://doi.org/10.1016/j.nano.2015.11.005 (2016).

24. Sondi, I. \& Salopek-Sondi, B. Silver nanoparticles as antimicrobial agent: A case study on E. coli as a model for Gram-negative bacteria. J. Colloid Interface Sci. 275, 177-182, https://doi.org/10.1016/j.jcis.2004.02.012 (2004).

25. Wei, Y. et al. Synthesis of Stable, Low-Dispersity Copper Nanoparticles and Nanorods and Their Antifungal and Catalytic Properties. J. Phys. Chem. C 114, 15612-15616, https://doi.org/10.1021/jp1055683 (2010).

26. Xiu, Z.-M., Zhang, Q.-B., Puppala, H. L., Colvin, V. L. \& Alvarez, P. J. J. Negligible particle-specific antibacterial activity of silver nanoparticles. Nano Lett. 12, 4271-5, https://doi.org/10.1021/nl301934w (2012).

27. Zhao, Y. et al. Small Molecule-Capped Gold Nanoparticles as Potent Antibacterial Agents That Target Gram-Negative Bacteria. J. Am. Chem. Soc. 132, 12349-12356, https://doi.org/10.1021/ja1028843 (2010).

28. Zhou, Y., Kong, Y., Kundu, S., Cirillo, J. D. \& Liang, H. Antibacterial activities of gold and silver nanoparticles against Escherichia coli and bacillus Calmette-Guérin. J. Nanobiotechnology 10, 19-19, https://doi.org/10.1186/1477-3155-10-19 (2012).

29. Durán, N. et al. Silver nanoparticles: A new view on mechanistic aspects on antimicrobial activity. Nanomedicine: Nanotechnology, Biol. Medicine 12, 789-799, https://doi.org/10.1016/j.nano.2015.11.016 (2016).

30. Ivask, A. et al. Toxicity Mechanisms in Escherichia coli Vary for Silver Nanoparticles and Differ from Ionic Silver. ACS Nano 8 , 374-386, https://doi.org/10.1021/nn4044047 (2014).

31. Rai, M., Yadav, A. \& Gade, A. Silver nanoparticles as a new generation of antimicrobials. Biotechnol. Adv. 27, 76-83, https://doi. org/10.1016/j.biotechadv.2008.09.002 (2009).

32. Graves, J. L. et al. Rapid evolution of silver nanoparticle resistance in Escherichia coli. Front. Genet. 5, 1-13, https://doi.org/10.3389/ fgene.2015.00042 (2015).

33. Deshpande, L. \& Chopade, B. Plasmid mediated silver resistance in Acinetobacter baumannii. Biometals 7, 49-56, https://doi. org/10.1007/BF00205194 (1994).

34. Li, X. Z., Nikaido, H. \& Williams, K. E. Silver-resistant mutants of Escherichia coli display active efflux of $\mathrm{Ag}^{+}$and are deficient in porins. J. Bacteriol. 179, 6127-6132, https://doi.org/10.1128/CMR.00043-12 (1997).

35. Gogoi, S. K. et al. Green Fluorescent Protein-Expressing Escherichia coli as a Model System for Investigating the Antimicrobial Activities of Silver Nanoparticles. Langmuir 22, 9322-9328, https://doi.org/10.1021/la060661v (2006).

36. Schneider, C. A., Rasband, W. S. \& Eliceiri, K. W. NIH Image to ImageJ: 25 years of image analysis. Nat. Methods 9, 671-675, https:// doi.org/10.1038/nmeth.2089 (2012)

37. Schindelin, J. et al. Fiji: An open-source platform for biological-image analysis. Nat. Methods 9, 676, https://doi.org/10.1038/ nmeth.2019 (2012).

38. Ducret, A., Quardokus, E. M. \& Brun, Y. V. MicrobeJ, a tool for high throughput bacterial cell detection and quantitative analysis. Nat. Microbiol. 1, 16077, https://doi.org/10.1038/nmicrobiol.2016.77 (2016).

39. Paintdakhi, A. et al. Oufti: an integrated software package for high-accuracy, high-throughput quantitative microscopy analysis. Mol. Microbiol. 99, 767-777, https://doi.org/10.1111/mmi.13264 (2016).

40. Oliphant, T. E. Guide to NumPy 2nd edn, (CreateSpace Independent Publishing Platform, USA, 2015).

41. Jones, E., Oliphant, T. \& Peterson, P. \{SciPy\}: Open source scientific tools for $\{$ Python\}. Online (2001-///)

42. Robert, L. et al. Division in Escherichia coli is triggered by a size-sensing rather than a timing mechanism. BMC Biol. 12, 17-17, https://doi.org/10.1186/1741-7007-12-17 (2014).

43. Stoica, P. Spectral Analysis of Signals 1st edition edn, (Prentice Hall, Upper Saddle River, N. J, 2005)

44. Welch, P. The use of fast Fourier transform for the estimation of power spectra: A method based on time averaging over short, modified periodograms. IEEE Trans. Audio Electroacoustics 15, 70-73, https://doi.org/10.1109/TAU.1967.1161901 (1967).

45. Lotka, A. J. Contribution to the Theory of Periodic Reactions. J. Phys. Chem. 14, 271-274, https://doi.org/10.1021/j150111a004 (1909).

46. Shih, H.-Y. \& Goldenfeld, N. Path-integral calculation for the emergence of rapid evolution from demographic stochasticity. Phys. Rev. E 90, 050702, https://doi.org/10.1103/PhysRevE.90.050702 (2014).

47. Silver, S. Bacterial silver resistance: molecular biology and uses and misuses of silver compounds. FEMS Microbiol. Rev. 27, 341-353, https://doi.org/10.1016/S0168-6445(03)00047-0 (2003).

48. Nies, D. H. Efflux-mediated heavy metal resistance in prokaryotes. FEMS Microbiol. Rev. 27, 313-339, https://doi.org/10.1016/ S0168-6445(03)00048-2 (2003).

49. Dougan, D. A., Mogk, A. \& Bukau, B. Protein folding and degradation in bacteria: to degrade or not to degrade? that is the question. Cell. Mol. Life Sci. 59, 1607-1616, https://doi.org/10.1007/\{PL00012487\} (2002).

50. Cooper, G. M. \& Hausman, R. E. The Cell: A Molecular Approach, Sixth Edition 6 edn, (Sinauer Associates, Inc., 2013).

51. Gillespie, D. T. A general method for numerically simulating the stochastic time evolution of coupled chemical reactions. J. Comput. Phys. 22, 403-434, https://doi.org/10.1016/0021-9991(76)90041-3 (1976).

52. Gillespie, D. T. Exact stochastic simulation of coupled chemical reactions. J. Phys. Chem. 81, 2340-2361, https://doi.org/10.1021/ j100540a008 (1977).

53. Jung, W. K. et al. Antibacterial Activity and Mechanism of Action of the Silver Ion in Staphylococcus aureus and Escherichia coli. Appl. Environ. Microbiol. 74, 2171-2178, https://doi.org/10.1128/AEM.02001-07 (2008).

54. Kruse, K. \& Jülicher, F. Oscillations in cell biology. Curr. Opin. Cell Biol. 17, 20-26, https://doi.org/10.1016/j.ceb.2004.12.007 (2005).

55. Vecchiarelli, A. G. et al. Membrane-bound MinDE complex acts as a toggle switch that drives min oscillation coupled to cytoplasmic depletion of MinD. Proc. Natl. Acad. Sci. United States Am. 113, E1479-88, https://doi.org/10.1073/pnas.1600644113 (2016).

56. Sherratt, D. J. Oscillation helps to get division right. PNAS 113, 2803-2805, https://doi.org/10.1073/pnas.1601792113 (2016).

57. Tanouchi, Y. et al. A noisy linear map underlies oscillations in cell size and gene expression in bacteria. Nat. 523, 357-360, https:// doi.org/10.1038/nature14562 (2015).

58. Franke, S., Grass, G. \& Nies, D. H. The product of the ybdE gene of the escherichia coli chromosome is involved in detoxification of silver ions. Microbiol. 147, 965-972, https://doi.org/10.1099/00221287-147-4-965 (2001).

59. Baba, T. et al. Construction of Escherichia coli K-12 in-frame, single-gene knockout mutants: The Keio collection. Mol. Syst. Biol. 2, 2006.0008-2006.0008, https://doi.org/10.1038/msb4100050 (2006).

60. Randall, C. P., Gupta, A., Jackson, N., Busse, D. \& O’Neill, A. J. Silver resistance in gram-negative bacteria: a dissection of endogenous and exogenous mechanisms. The J. Antimicrob. Chemother. 70, 1037-1046, https://doi.org/10.1093/jac/dku523 (2015).

61. Toprak, E. et al. Evolutionary paths to antibiotic resistance under dynamically sustained drug selection. Nat. Genet. 44, 101-105, https://doi.org/10.1038/ng.1034 (2011). 
62. Toprak, E. et al. Building a morbidostat: An automated continuous-culture device for studying bacterial drug resistance under dynamically sustained drug inhibition. Nat. Protoc. 8, 555-67, https://doi.org/10.1038/nprot.nprot.2013.021 (2013).

63. Mazouchi, A. \& Milstein, J. N. Fast Optimized Cluster Algorithm for Localizations (FOCAL): A spatial cluster analysis for superresolved microscopy. Bioinforma. 32, 747-754, https://doi.org/10.1093/bioinformatics/btv630 (2016).

64. Zhang, M. et al. Rational design of true monomeric and bright photoactivatable fluorescent proteins. Nat. Methods 9, 727-9, https:// doi.org/10.1038/nmeth.2021 (2012).

65. Sadoon, A. A. \& Wang, Y. Anomalous, non-Gaussian, viscoelastic, and age-dependent dynamics of histonelike nucleoid-structuring proteins in live Escherichia coli. Phys. Rev. E 98, 042411, https://doi.org/10.1103/PhysRevE.98.042411 (2018).

66. Alqahtany, M. et al. Nanoscale reorganizations of histone-like nucleoid structuring proteins in are caused by silver nanoparticles. Nanotechnology 30(38), 385101, https://doi.org/10.1088/1361-6528/ab2a9f (2019).

67. Edelstein, A., Amodaj, N., Hoover, K., Vale, R. \& Stuurman, N. Computer Control of Microscopes Using Micro-Manager. In Current Protocols in Molecular Biology, https://doi.org/10.1002/0471142727.mb1420s92 (John Wiley \& Sons, Inc., Hoboken, NJ, USA, 2010).

68. Guizar-Sicairos, M., Thurman, S. T. \& Fienup, J. R. Efficient subpixel image registration algorithms. Opt. Lett., OL 33, 156-158, https://doi.org/10.1364/OL.33.000156 (2008).

69. van der Walt, S. et al. Scikit-image: Image processing in Python. PeerJ 2, e453, https://doi.org/10.7717/peerj.453 (2014).

70. Sternberg. Biomedical Image Processing. Comput. 16, 22-34, https://doi.org/10.1109/MC.1983.1654163 (1983).

\section{Acknowledgements}

This work was supported by the University of Arkansas, the Arkansas Biosciences Institute (Grant No. ABI-0189, No. ABI-0226, No. ABI-0277, No. ABI-0326), and the National Science Foundation (Grant No. 1826642). We are also grateful for supports from the Arkansas High Performance Computing Center (AHPCC), which is funded in part by the National Science Foundation (Grants No. 0722625, 0959124, 0963249, 0918970) and the Arkansas Science and Technology Authority.

\section{Author Contributions}

Y.W. and J.C. conceived the project; V.R.K. carried out the experiments; V.R.K. and Y.W. performed the data analysis and developed the model. V.R.K., J.C. and Y.W. wrote, revised and reviewed the manuscript.

\section{Additional Information}

Supplementary information accompanies this paper at https://doi.org/10.1038/s41598-019-48113-4.

Competing Interests: The authors declare no competing interests.

Publisher's note: Springer Nature remains neutral with regard to jurisdictional claims in published maps and institutional affiliations.

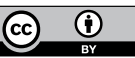

Open Access This article is licensed under a Creative Commons Attribution 4.0 International License, which permits use, sharing, adaptation, distribution and reproduction in any medium or format, as long as you give appropriate credit to the original author(s) and the source, provide a link to the Creative Commons license, and indicate if changes were made. The images or other third party material in this article are included in the article's Creative Commons license, unless indicated otherwise in a credit line to the material. If material is not included in the article's Creative Commons license and your intended use is not permitted by statutory regulation or exceeds the permitted use, you will need to obtain permission directly from the copyright holder. To view a copy of this license, visit http://creativecommons.org/licenses/by/4.0/.

(C) The Author(s) 2019 